\title{
Expression Plane of English Idioms in Gender Semantics Studies
}

\author{
Galina Nezhelskaya*, Varvara Samarina, and Oksana Shibkova
}

Department of Foreign Languages for Humanities and Natural Sciences, North-Caucasus Federal University, Stavropol, Russia, galnezh@mail.ru

\begin{abstract}
In recent years gender studies have become connected with language studies, because language reflects, records and transmits social, cultural and gender differences. Idioms in any language transfer underlying ideas, principles and values of this particular society or culture, so they are considered as the main source for gender studies in linguistics. This paper deals with corpus-based studies of English idioms with gender components. The authors analyze the expression plane of English idioms and give a model representation of English gender-marked idioms. The method of identification of key lexical items has been applied. As a result, the dominant gender lexical items in English gender-marked idioms have been identified and ranked on the basis of their frequency. The authors have also revealed the most/least common gender components and gender oppositions in English idioms.
\end{abstract}

\section{Introduction}

Gender issues have been studied in many disciplines such as psychology, sociology, anthropology, literature, political sciences and others. Language reflects, records and transmits social, cultural and gender differences so the explosion of interest in gender semantics in recent years is quite understandable. The expansion of linguistic field of studies caused by the paradigm shift away from focusing on language structure onto focusing on anthropocentric issues has also contributed to gender reflection in the scientific study of language. Idioms transferring underlying ideas, principles and values of a given society or culture in our opinion are especially good source for gender studies. There are two approaches to gender studies in linguistics: 1) the reflection of gender differences and general social ideas about a man and a woman in language, particularly in its vocabulary and grammar, and 2) the study of male-female communicative behavior (male-female using of language). Our research of English idioms with gender semantics was carried out within the first approach.

\section{Methodology}

We are convinced that by applying lingvocultural approaches and cognitive linguistics methods to gender studies, we can clarify gender semantics of idioms, give a model representation of English gender-marked idioms, and explore gender lingvocultural indicators in idiomatic corpus [1]. There is a variety of methods used for investigation of idioms and their characteristics, for example, method of identification of key lexical items. We have applied this method in our research because it allows identifying the dominant lexical items in the corpus of idioms. Dominants of the expression plane of English idioms are selected in the process of sampling. In subsequent research stages, linguists deal with a sample that is more or less limited in both the formal and the semantic aspects. In phraseology, the quantitative prevalence in such a sample is considered as one of the important factors, but unique features of idioms are also taken into consideration. The analysis of the expression plane of English idioms in the first stage of research makes it possible to rank the lexical items on the basis of their frequency. This kind of analysis does not involve indicating of absolute or relative frequency of lexical items, so in our research we have only indicated the frequency rank of lexical items with gender semantic. The sampling has involved the analysis of full extracts of gender-marked English idioms from the following sources: "Longman Dictionary of Contemporary English", "Longman Idioms Dictionary", "New Webster's Dictionary of The English Language", "Oxford Advanced Learner's Dictionary of Current English" ed. A.S. Hornby, "Macmillan English Dictionary", some dictionaries by Russian authors, the Internet resources. [213]

\section{Results and discussion}

The analysis of more than 300 sampled gender-marked English idioms allow us to rank them on the basis of their frequency.

English idioms with gender component man are ranked first, because it is the most common component of

* Corresponding author: galnezh@mail.ru 
English gender-marked idioms (the component frequency is given in round brackets).

1. man (113), for example:

- a bad man - 1) any outlaw or criminal, desperado; 2) the villain in a motion picture, play, television show, or other theatrical performance;

- best man - the man who helps the bridegroom at a wedding ceremony;

- a liberty man - a sailor with permission to go ashore;

- a little man - a boy;

- a plain-clothes man - a policeman or detective wearing ordinary clothes, not a uniform, when on duty;

- a strong-arm man - a bully; a man who is employed to use physical power to force someone to do something;

- a man's man - a man who enjoys being with other men and doing sports and activities with them, and is popular with men rather than women;

- angry young man - a young man who strongly criticizes society and the government (the phrase was first used to describe John Osborne and other British writers in the 1950s);

- between man and man (man to man) - between two men who are treating each other honestly and equally;

- undercover man - 1) one who undertakes to secure evidence of criminal or illegal actions by working with or among those who are under suspicion; 2) one who secures a position (as in a business or factory) for the purpose of illicitly obtaining confidential information.

Idioms with gender components boy, girl, woman and lady are ranked second.

2.1. boy (31), for example:

- cabin boy - a young man who works as a servant on a ship;

- a ball boy - a boy who picks up the balls for people playing in important tennis matches;

- a mummy's boy/a mother's boy/mamma's boya boy or man who lets his mother look after him and protect him too much, so that people think he is weak;

- old boy - 1) a man who used to be a student at a school; 2) an old man; 3 ) used when speaking to a male friend;

- city/local/country boy - a man of any age who is typical of people from a particular place, or who feels a strong connection with the place he grew up in;

- the boys in blue - the police;

- office/paper/delivery etc boy - a young man who does a particular job;

- bully boy - someone who behaves in a violent and threatening way.

2.2. girl (29), for example:

- a bachelor girl - an unmarried young woman who works and leads an independent life;

- a golden girl - a girl who is popular and successful;

- a girl Friday - a girl or woman worker who does several different jobs in an office (based on Man Friday, a character in the book Robinson Crusoe (1719) who does jobs for the main character, Robinson Crusoe);

- paper girl - a girl who delivers newspapers to people's houses;

- a glamour girl - a performer who is more noticeable for their attractiveness than for their skill or ability;

- alpha girl - a teenage girl who is the most important and powerful member of a group of girls who regularly spend time together; alpha girls are typically confident, attractive, and determined to be successful (often used humorously);

- cover girl - an attractive young woman whose photograph is on the front cover of a magazine;

- a call girl - a prostitute who arranges by telephone to meet men;

- a weather girl - a woman on television or radio who tells you what the weather will be like;

- principal girl - the main female role in a pantomime;

- a big (great) girl's blouse - someone, especially a man, who is not brave;

- old girl - 1) an old woman; 2) a woman who is a former student of a school.

2.3. mother (28), for example:

- mother's help - a person employed to help a mother with domestic duties, esp. the supervision of children;

- mother country - someone's mother country is the country in which they or their ancestors were born and to which they still feel emotionally linked, even if they live somewhere else;

- Mother Nature - used to refer to the natural world as if it were a woman;

- Mother Superior - a woman who is the head of a religious establishment (often used as a title);

- at your mother's knee - if you learned to do something at your mother's knee, you learned it when you were a young child;

- mother tongue - the first and main language that you learnt when you were a child;

- mother's mark - a birthmark;

- like a mother hen - if someone behaves like a mother hen, they try to protect their children too much and worry about them all the time;

- hit the mother lode - to produce or find something that will make you very rich, happy, or successful;

- mother lode - 1) a mine that is full of gold, silver etc.; 2) a place where you can find a lot of a particular type of object.

2.4. woman (27), for example:

- my good woman - a patronizing form of address 
to a woman;

- the other woman - used to refer to a woman with whom a man is having a sexual relationship, even though he already has a wife or partner;

- scarlet woman - a woman who has sexual relationships with many different people;

- well-woman - providing medical care and advice for women, to make sure that they stay healthy;

- kept woman - a woman who is given a place to live, money, and clothes by a man who visits her for sex (often used humorously);

- fancy woman - a woman that a married man has a sexual relationship with, who is not his wife;

- Renaissance woman - a man or woman who can do many things well, such as writing and painting, and who knows a lot about many different subjects;

- a woman of the world - to be someone who has had many experiences and is not easily shocked;

- somebody's old woman - someone's wife or mother.

2.5. lady (27), for example:

- Our Lady - Mary, the mother of Christ;

- bag lady - an impolite word for a homeless woman who lives on the streets and carries all her possessions with her;

- the lady of the house - the most important woman in a house, usually the mother of a family;

- lady friend - a woman that a man is having a romantic relationship with, a girlfriend (often used humorously);

- dinner lady - a woman who serves meals to children at school;

- lady killer - an attractive, charming man who habitually seduces women (informal);

- Lady Muck - a woman who has a very high opinion of her own importance, and expects people to do things for her;

- lollipop lady - someone whose job is to help children cross a road safely on their way to school.

The following idioms are ranked idioms with gender components son and gentleman:

3.1. son (13), for example:

- son of a bitch - 1) an offensive expression for a man that you are very angry with; 2) used when you are annoyed or surprised;

- son of a gun - 1) a man you like or admire (used humorously); 2) a man that you are annoyed with; 3) an object that is difficult to deal with (used humorously); 4) used to express surprise;

- son et lumiere - a performance that tells the story of a historical place or event using lights and recorded sound;

- favorite son - a politician, sports player etc. who is popular with people in the place that they come from;

- my son - used by a priest to address a man or boy;

- the prodigal son - someone who leaves their family and home without the approval of their family, but who is sorry later and returns;

- the Son of God (of Man) - used by Christians to mean Jesus Christ.

3.2. gentleman (11), for example:

- gentleman/lady of leisure - someone who does not have to work (used humorously);

- gentleman farmer - a man belonging to a high social class who owns and runs a farm, but who usually hires people to do the work;

- the Honourable Gentleman - used by British members of parliament when talking to or about each other in the House of Commons;

- gentleman's gentleman - a rich man's personal servant;

- gentleman's agreement - an agreement that is not written down, made between people who trust each other.

Last idioms are ranked idioms with gender components daddy, wife, fellow, daughter, widow, dame and husband, their frequency is less than 10:

4.1. daddy (6), for example:

- sugar daddy - an older man who gives a young person presents and money in return for their company and often for sex;

4.2. wife (5), for example:

- wife beater - a man who often hits his wife;

- trophy wife - a young beautiful woman who is married to a rich successful man who is much older than her (used to show disapproval);

4.3. fellow (5), for example:

- fellow feeling - a feeling of sympathy and friendship towards someone because they are like you;

- fellow traveler - someone who supports and agrees with the beliefs of an organization, such as the Communist Party, but does not belong to it (used to show disapproval);

4.4. daughter (4), for example:

- Daughters of the American Revolution - a US organization for women who are descended from people who fought or helped in the American Revolution; the group was established in 1890, it is very conservative and supports anything it believes is good for America;

4.5. widow (3), for example:

- war widow - a woman whose husband has been killed in a war;

- football, golf, etc. widow - a woman whose husband spends all his free time watching football, playing golf etc (used humorously);

4.6. dame (2), for example:

- Dame commander - (in Britain) the title of a woman who has been given one of a particular set of honours by the King or Queen;

4.7. husband (2), for example:

- house husband - a husband who stays at home and does the cooking, cleaning etc.

Having examined the sampled gender components (taking into account their rank weight), we have made the following list of gender oppositions: 
- $\operatorname{man}(1)-\boldsymbol{w o m a n}(2)$;

- boy (2) - girl (2);

- mother (2) - 0;

- son (2)-daughter (4);

- lady (2)-gentleman (4);

- wife (4) - husband (4).

The figure in round brackets indicates the ranking place of the lexical item, zero means that there is no gender opposition for this particular lexical item.

In the next stage of our research we analyzed the usage of proper nouns in the sampled idioms. The results are presented in Table 1 and Table 2.

Table 1. Proper nouns used in English idioms.

\begin{tabular}{|c|c|}
\hline $\begin{array}{c}\text { Proper nouns used in } \\
\text { "masculine" idioms }\end{array}$ & $\begin{array}{c}\text { Proper nouns used in } \\
\text { "feminine" idioms }\end{array}$ \\
\hline Adam & Teddy \\
Mars & Babylon \\
Neptune & Threadneedle Street \\
David & Hubbard \\
Jonathan & Caesar \\
Jack & Eve \\
Friday & Maria \\
Europe & Rome \\
\hline
\end{tabular}

Table 2. Common names used in the role of proper nouns in English idioms.

\begin{tabular}{|c|c|}
\hline "Masculine" idioms & "Feminine" idioms \\
\hline & Bountiful \\
& Luck \\
Muck \\
Bunch \\
& Scavenger \\
\hline
\end{tabular}

As can be seen from Table 1 and Table 2, in English gender-marked idioms, masculine and feminine proper nouns are used equally, but taking into account common names used as proper nouns we can speak about the predominance of feminine proper names in English idioms with gender semantics. The analysis has revealed that there are mythological, historical, literary and biblical proper names in English idioms, for example, Adam, Eve, Caesar, Mars, and three toponyms: the Lady of Babylon, the Lady of Rome, and the old lady in/of Threadneedle street. The usage of common names in the role of proper nouns is another feature of English idioms, for example, Mother Bunch (bunch is a common name that means a number of things of the same type which are growing or fastened together, for example, bunch of flowers) - a stout, untidy, or awkward-looking woman or girl (from the name of Mother Bunch, an alehouse keeper in Elizabethan London, renowned for serving particularly strong ale, and reputed to have lived to a great age).

It has also been found out that, in general, the proper nouns in the examined English idioms can be represented in the following situations:

1. In the situation of gender correspondence, when a masculine proper noun is used in idioms with masculine semantics, for example:

- son of Adam - any man or boy;
- a son of Mars - military man;

- a son of Neptune - seaman;

and a feminine proper noun is used in idioms with feminine semantics, for example:

- the daughter of Eve (Eve's daughter) - 1. a) a female child; a girl is the daughter of her father and mother; b) a daughter-in law; c) a kindly term of address to a girl as from an older person, priest, or the like; 2. a female descendant.

2. In the situation of gender discrepancy, when a masculine proper noun is a component of idioms with feminine semantics, for example:

- Caesar's wife - a person required to be above suspicion;

- Nancy (or pansy) boy - an offensive word for a homosexual man, or a man who behaves in a way that is thought to be typical of women.

3 . In the situation of gender ambivalence when the same proper noun is used in idioms with masculine and feminine semantics, for example:

- a Teddy girl / a Teddy boy - a member of a group of young men in Britain in the 1950s who had their own special style of clothes and music;

- Man Friday / a girl Friday - a loyal and trusted servant or helper / a female assistant, especially a junior office worker (based on Man Friday, a character in the book Robinson Crusoe (1719) who does jobs for the main character, Robinson Crusoe. He is a black man who becomes Crusoe's servant and friend after Crusoe saves him from being killed by cannibals. Crusoe calls him Man Friday because he met him on a Friday).

4. In the lack of gender motivation situation, when proper nouns are used in idioms which are not gendermarked, for example:

- the old lady in (of) Threadneedle Street - a nickname for the Bank of England, which is in Threadneedle Street in the City of London.

According to their grammatical structure the examined English idioms have been classified as nominal idioms (about 88\%), because they have objective (in a broad sense) meaning; idioms-sentences (about 8\%), procedural idioms and idioms with adverbial meaning (2\% each). Besides there are also isolated idiomsexclamations.

The majority of idioms in the sample are referred to a nominal type, that is, their grammatical structure contains various combinations with the noun name.

1. The adjective + noun combination is the prevailing one - 65 idioms: principal boy, a golden girl, old girl, the outer man, a strong man, etc.

2 . The noun + noun combination is ranked second 56 idioms: a grass widow, call girl, flower girl, etc.

3 . The noun + of + noun combination is ranked third 42 idioms: a woman of letters, the man of iron, the Man of Sorrows, the bride of the sea, son of heaven, a man of straw, etc.

4. The noun's + noun combination is ranked last - only 13 idioms: ladies' (lady's) man, etc.

Other grammatical structures are not commonly used 
in English idioms with gender components. For instance, there are only four examples of verbal idioms (with a verb as a key component) in our sample: two of them are referred to verb + noun combination (practically identical idioms play the woman and play the man). Besides, these are idioms with verb + adjective + noun structure (feel (like) a new man) and verb + adjective + adjective + noun structure (refresh one's inner man).

\section{Conclusion}

To sum up, analyzing the expression plane of English idioms, we have identified and ranked (on the basis of their frequency) the lexical items with gender semantics in the sampled English gender-marked idioms. The following conclusions can be drawn: first, the most common gender opposition in English idioms is man woman; second, gender components in English idioms are expressed by proper nouns, terms reflecting kinship and other gender-marked lexical items. Third, the analysis of expression plane can be applied to the investigation of idioms with non-gender semantics.

\section{References}

1. V.S. Samarina, G.N. Nezhelskaya, L.G. Gubanova Issues of Cog. Ling. 2(51), pp. 118-126 (2017)

2. Cambridge Advanced Learner's Dictionary (Cambridge: Cambridge University Press, 2003)

3. A.S. Hornby, Oxford Advanced Learner's Dictionary of Current English (Oxford: Oxford University Press, 2000)

4. Longman Dictionary of Contemporary English, (Harlow: Pearson Education Limited, 2003)

5. Longman Idioms Dictionary (Harlow: Pearson Education Limited, 2002)

6. Macmillan English Dictionary (Oxford: Macmillan Education, 2002)

7. New Webster's Dictionary of the English Language (Delhi: Surjeet Publications, 1999)

8. Oxford Dictionary of English Etymology (Oxford: Oxford University Press, 1996)

9. A.V. Kunin, The Bilg English-Russian Fraseological Dictionary (Moscow: Russian Language Press Media, 2005)

10. S.F. Kuskovskaya, Collection of English proverbs and sayings (Moscow: Higher School Press, 1987)

11. S.I. Lubenskaya, Russian-English Fraseological Dictionary (Moscow: Languages of Russian Culture, 1997)

12. New Big English-Russian Dictionary (Moscow: Russian Language Press 1,2,3, 1999)

13. http://www.oxforddictionaries.com - online dictionary by Oxford University Press 